REVISTA ANDALUZA DE ANTROPOLOGÍA.

NÚMERO 5: APORTACIONES Y POTENCIALIDADES DE LA ANTROPOLOGÍA DE LA SALUD.

SEPTIEMBRE DE 2013

ISSN 2174-6796

[pp. 35-65]

http://dx.doi.org/10.12795/RAA.2013.i05.03

Fecha de Recepción: 19-05-2013

Fecha de Aceptación: 30-06-2013

\title{
SACUDIRSE LA TUTELA MÉDICA. HACIA LA DESPATOLOGIZACIÓN DE LA TRANSEXUALIDAD
}

Fernando Tena

Hospital Universitario Reina Sofía (Servicio Andaluz de Salud)

Grupo de Investigación GEISA

\section{Resumen.}

Entre el gran número de fenómenos de la experiencia humana que fueron resignificados por la medicina como enfermedad, este artículo se centra en aquellas personas con una identidad de género distinta a la que les fue asignada al nacimiento. Estas personas han sido nombradas por la medicina como transexuales y el fenómeno correspondiente con el nombre común de transexualidad.

Usando los datos de un trabajo de campo desarrollado entre los años 2001 y 2006, junto a una última revisión documental, el autor muestra la evolución de las reivindicaciones del movimiento asociativo transexual en el Estado español. En un primer momento, las asociaciones transexuales asumieron el discurso de la enfermedad que permitió solicitar la inclusión de los tratamientos asociados en el sistema público sanitario. Sin embargo, desde hace unos diez años, líderes del movimiento transexual español se manifiestan en contra de esta psiquiatrización de las identidades trans. Esta petición desemboca en la campaña STOP PATOLOGIZACIÓN 2012 cuyos objetivos principales son la retirada de la categoría de "disforia de género" / "trastornos de la identidad de género" de los catálogos diagnósticos (DSM de la American Psychiatric Association y CIE de la Organización Mundial de la Salud), en sus próximas ediciones previstas para el 2013 y 2015, así como la lucha por los derechos sanitarios de las personas trans.

Palabras clave: medicalización, antropología, salud, transexualidad, género, movimientos sociales. 


\begin{abstract}
.
Among the large number of phenomena of human experience that were interpreted by the medicine as a disease, this article discusses the problems of those people with a gender identity different from the one they were assigned at birth. These people have been named by medicine as transsexuals and the corresponding phenomenowith the common name of transsexuality

Using data from a field work developed between 2001 and 2006, along with a final document review, the author shows the evolution of the claims of the transsexual movement in Spain.Initially, the transsexuals associations took the speech of the disease which allowed to ask for associated therapies to be included in the public health system. Howewer, since about ten years ago, leaders of the Spanish transsexual movement manifested against this psychiatrization of transidentities. The maingoalsof the Campaign are the removal of the categories of "gender dysphoria" / "gender identity disorders" from the diagnosis manuals (DSM of the American Psychiatric Association and ICD of the World Health Organization), whose newly revised versions are due in 2013 and 2015, as well as the fight for trans health rights.
\end{abstract}

Keywords: medicalization, anthropology, health, transsexualism, gender, social movements.

\title{
1. BREVE INTRODUCCIÓN SOBRE LA CONSTRUCCIÓN MÉDICA DEL PROBLEMA TRANSEXUAL
}

La pregunta: “¿Quiénes son enfermos mentales?” encuentra, por ende, esta respuesta: "Aquellos que se hallan internados en hospitales neuropsiquiátricos o acuden a los consultorios privados de los psiquiatras"

Thomas Szasz, El mito de la enfermedad mental, 1994 [1961], p.6

El filósofo francés Michel Foucault demostró un precoz interés por estudiar el proceso histórico por el que el saber y la tecnología de la medicina se convirtieron en un instrumento de control social en los estados europeos. Foucault define la medicalización como «el hecho de que la existencia, la conducta, el comportamiento, el cuerpo humano, se incorporaran a partir del siglo XVIII en una red [...] cada vez más densa y más amplia, que cuanto más funciona menos se escapa a la medicina» (1990: 122). Tal densidad y tal amplitud dan cuenta de que un cada vez mayor número de fenómenos de la experiencia humana fuera re-significado como un problema médico, sea esto nombrado como patología, enfermedad o trastorno.

Durante este proceso, una vez afianzadas sendas alianzas con el Estado y la Iglesia, la 
medicina asumió un mayor número de competencias ${ }^{1}$. Así, a modo de ejemplos, la disciplina médica decidió sobre la vida y la muerte; las normas de crianza a observar por las madres, cuidadoras "naturales" de las nuevas generaciones de la patria; convirtió la mayor parte del ciclo vital de la mujer en una sucesión de etapas mórbidas; asesoró sobre las condiciones laborales óptimas para la salud; quiénes podían trabajar y quiénes no; quiénes eran sujetos a tutelar por el Estado; se encargó de las alteraciones de la productividad y el consumo. Pero también, en un periodo en el que la sexualidad fue situada en el centro del discurso social (Foucault,1998a) no obstante como energía peligrosa a la que convenía controlar para asegurar la paz y la tranquilidad sociales (Weeks, 1993), a la vez que las mujeres reivindicaban unos derechos que exigían revisar el orden socio-sexual y la relaciones entre los grupos sociales de género, la medicina definió tanto las características del hombre y de la mujer normales como las prácticas sexuales adecuadas. $\mathrm{O}$ expresado en otros términos, como disciplina encargada de velar por la salud del orden social, la medicina asumió la competencia de diagnosticar y curar a todas aquellas personas cuyos cuerpos y experiencias rebasasen los límites de lo socialmente permitido.

Es en este contexto de vasos comunicantes entre el interés social y el interés científico, donde deseo encuadrar el exacerbado interés de los médicos que constituyeron el grupo de sexólogos pioneros decimonónicos, por estudiar a todas aquellas personas que, por transgredir las normas sociales sobre los cuerpos, los sexos, los géneros, las sexualidades $y$, por último, las identidades como seres sexuados, ocasionaban tanta pestilencia social ${ }^{2}$. A ellos, los sexólogos, correspondió la tarea de redefinir las prácticas y experiencias socialmente molestas -en los ámbitos de la erótica, el género y la identidad de génerocomo prácticas enfermas. Nacieron de este modo tres diagnósticos y tres especies enfermas de otros sexuales: homosexuales, transvestistas y transexuales, que comenzaron a desfilar por unas consultas médicas convertidas en templos destinados a la salvación (Tena, 2010: 5).

1. Comelles y Martínez escriben que los médicos desarrollaron "estrategias corporativas destinadas a asegurar el monopolio sobre la atención en salud" (1993: 8) que incluyeron su alianza con las élites poderosas de los estados europeos de tal manera que, derribando uno de los mitos de la historia épica de la medicina, los médicos afianzaron su poder históricamente desde su oficialidad y no desde su eficacia (Ehrenreich y English, 1984).

2. La mayoría de estos sexólogos participaban de las normas morales de su mundo social. Por este motivo tradujeron a problema teórico el problema social planteado por quienes no cumplían las prescripciones culturales sobre la orientación sexual -la dirección del deseo erótico hacia uno u otro sexo-, el género -permítaseme, aunque de forma simplista, definirlo como el conjunto de características culturalmente asignadas a los hombres y a las mujeres- o la identidad de género -el sentimiento de ser un varón o una mujer (Tena, 2010: 5). Y lo hicieron así porque cualquier experiencia que resultara una desviación de las normas morales podía ser potencialmente considerada como una enfermedad (Weeks, 1993: 130). 
Centrándonos en el último de los grupos enumerados, el constituido por quienes manifestaban una identidad de género distinta a la asignada a su nacimiento en función de sus genitales externos, a lo largo del siglo XX la medicina había conseguido la tecnología médico-quirúrgica elemental que permitía la transformación de sus cuerpos. En efecto, los descubrimientos biológicos y el perfeccionamiento de las técnicas quirúrgicas no dejaron de sucederse durante sus primeras décadas: cromosomas, hormonas esteroides, procedimientos anestésicos, técnicas específicas para "solucionar" la ambigüedad genital de las personas hermafroditas... Llegada la década de los años veinte, la tecnología médica de género para reconducir a los cuerpos y experiencias disidentes de la norma social, se encontraba ya disponible. Hacían falta dos claves: la primera, que la medicina justificara que era el cuerpo transexual -como ya lo había hecho en el caso del cuerpo hermafrodita- el elemento a modificar (Dreger, 2000); la segunda, que los y las pacientes solicitaran esta metamorfosis corporal para aliviar su sufrimiento.

La publicidad otorgada a casos comolos de Christine Jorgensen ${ }^{3}$-y otros más que colmaron los medios de comunicación- durante los años cincuenta del pasado siglo mostraron a la comunidad científica y a la población general los hechos extraordinarios, casi épicos, de machos fenotípicos transformados en hembras-mujeres gracias a la medicina. Así, a partir de la publicación del caso de la citada Christine y de su autobiografía (1967), aumentaron de forma espectacular las peticiones de hormonación y transformación

3. El punto de inflexión en el aumento de peticiones de la entonces llamada cirugía de cambio de sexo y de la divulgación de la transexualidad entre la población europea y norteamericana se produjo en la década de los cincuenta cuando la historia de George (después Christine) Jorgensen estalló como una bomba en la prensa estadounidense y europea. George Jorgensen era un macho fenotípico, criado como un varón, que trabajaba como técnico de laboratorio en un hospital de Nueva York. George se trasladó a Dinamarca y consultó con un endocrinólogo, Christian Hamburger, porque se sentía deprimido por llevar una vida como hombre. El equipo médico dirigido por Hamburger sometió al paciente a un examen físico y psiquiátrico y, no encontrando ninguna anomalía sino su deseo manifiesto por vivir como una mujer con un cuerpo de hembra, comenzó a suministrarle elevadas dosis de estrógenos por vía parenteral. Los cambios corporales provocados por el tratamiento de estrógenos se sucedieron. Posteriormente, se sometió a una castración -extirpación de testículos- en Dinamarca en el año 1951 y, un año más tarde, a una penectomía -extirpación del pene- en el mismo país. A la edad de 26 años, George volvía a Estados Unidos rebautizada como Christine -en honor de su médico- y se presentaba ante los expectantes medios de comunicación como una actriz de la Paramount. Su caso extraordinario la convirtió en una "sensación de los periódicos e indudablemente en la figura transexual más famosa del siglo XX. Ella era hermosa, rubia y representaba la idea común de la chica americana" (Wittle, 2000: 40). Dos años más tarde de las operaciones realizadas en Dinamarca, Christine Jorgens conseguía la hembridad deseada sometiéndose a una tercera intervención quirúrgica que le proporcionó una vagina (Jorgensen, 1967: 250-52). 
quirúrgica recibidas en las consultas médicas como consecuencia de una "inducción de la demanda" (Hausman, 1998: 198). La medicalización operó de tal manera sobre el fenómeno que nos ocupa que la tradición europea y nativa norteamericana de "transgresión del sexo por el género" sin intervención médica (Bullough, 1974; Ramet, 1996; Dekker y van de Pol, 2006) dio paso a lo que la antropóloga feminista Nicole Claude Mathieu nombra como una "transgresión del género por el sexo" para hacer referencia al modelo clínico de transexualidad (1991: 235).

Aunque los criterios diagnósticos se estaban construyendo desde hacía décadas -y se ensayaban tratamientos médico-quirúrgicos, aún sin explicación consensuada en la comunidad científica-, la consagración académica del fenómeno transexual como problema identitario cuya curación pivotaba en torno a la transformación corporal que propuso el equipo de Christian Hamburger en Dinamarca (1953) y Harry Benjamin en Estados Unidos $(1966)^{4}$ se produce cuando el transexualismo queda incluido tanto en la Clasificación Internacional de Enfermedades (CIE, 1975), como en el Manual Diagnóstico y Estadístico de los Trastornos Mentales (DSM-III, 1980) ${ }^{5}$. Y fue este discurso de la enfermedad el que continuó sedimentando progresivamente entre la población con una identidad de género distinta de la asignada al nacimiento. De la misma manera, las asociaciones transexuales fundadas en el Estado español tras la llegada de la democracia, durante los años ochenta, justificando su petición en la condición enferma, plantearon como un objetivo central la inclusión de los tratamientos médicos-quirúrgicos asociados a la transexualidad en la cartera de servicios del sistema nacional de salud.

Las transgresiones de género -que aquí entiendo como cualquier experiencia que impugne la homología entre sexo y género ${ }^{6}$ - y su proceso de medicalización centraron la investigación que constituyó mi tesis doctoral ${ }^{7}$. Entre otras técnicas y otros

4. Harry Benjamin fue un endocrinólogo y sexólogo alemán que emigró a Estados Unidos. Trató a la mujer transexual más famosa del siglo XX, Christine Jorgensen, junto a un equipo médico danés liderado por el endocrinólogo Christian Hamburger (1953). Benjamin es autor del libro referencia de este modelo clínico, The Transsexual Phenomenon (1966).

5. Se trata de sendos manuales taxonómicos de enfermedades; el primero, la Clasificación Internacional de Enfermedades (CIE), publicado por la Organización Mundial de la Salud; el segundo, el Manual Diagnóstico y Estadístico de Trastornos Mentales (DSM), por la Asociación Americana de Psiquiatría.

6. Nicole Claude Mathieu establece esta homología entre el sexo y el género -el género traduce al sexo, también expresa la autora (1991: 232)- como característica de una específica lógica identitaria que denomina "identidad sexual", la más frecuente tanto en la Academia como en el pensamiento común.

7. Los datos etnográficos han sido extraídos de la tesis doctoral titulada Los cuerpos equivocados. El proceso de medicalización de las transgresiones de género: el caso de la población transexual andaluza, defendida por el autor en el Departamento de Antropología Social de la Universidad de Sevilla en el año 2008. 
contextos de investigación, el trabajo de campo incluyó historias de vida y entrevistas semiestructuradas a personas con una identidad de género distinta a la asignada tras su nacimiento, además de revisión documental y observación participante en diversas asociaciones transexuales españolas en varias campañas comprendidas entre los años 2001 y 2006. Este trabajo de campo recogía la emergencia de un por entonces tímido discurso transexual, ahora consolidado y visible, que revisaba la construcción mórbida de su experiencia vital. Y no solo un discurso. Varias asociaciones transexuales españolas comenzaron a advertir, una cuestión sobre la que avanzaremos en el siguiente epígrafe, la necesidad de intervenir activamente en las instituciones políticas y científicas -sobre todo la Organización Mundial de la Salud, la Asociación Americana de Psiquiatría y la Harry Benjamin International GenderDysphoriaAssociation (HBIGDA)-, aquéllas desde las que se había legitimado la consideración de las personas transexuales como enfermas mentales y habían definido el necesario itinerario terapéutico y los estándares de calidad para su curación.

\section{DEL CUERPO EQUIVOCADO A LA CULTURA EQUIVOCADA}

\subsection{LA ENFERMEDAD MARCA UNA DIFERENCIA. DE LA LEGITIMIDAD COMO ENFERMEDAD A ¡NOSOTRAS NO SOMOS ENFERMAS!}

En sus inicios, las asociaciones transexuales estadounidenses -no olvidemos que fue Estados Unidos el contexto cultural donde se configura el diagnóstico transexualidad y su terapéutica en un viaje de ida y vuelta con Europa- mantuvieron una agenda política de reivindicaciones relacionadas con el modelo clínico. La enfermedad explicaba su existencia y sus peticiones. Una cuestión importante para este movimiento, en los inicios de su andadura, era evitar que la transexualidad se confundiera con la homosexualidad -siguiendo la terminología médica- en el pensamiento común ${ }^{8}$. Y fue precisamente este discurso de la enfermedad el que permitió que los y las transexuales pudieran establecer sus diferencias con las minorías homoeróticas que, rechazando la categoría homosexual,

\footnotetext{
8. Un ejemplo que ilustra esta cuestión es Agnes, paciente estudiada en los pasados años cincuenta y sesenta por el psiquiatra estadounidense Robert Stoller, figura destacada en el abordaje médico de la transexualidad. Agnes fue entrevistada en varias ocasiones por el sociólogo Harold Garkinfel que, además, observó la compleja negociación diagnóstica, destacando la insistencia de Agnes para apartarse de "niños que actuaban como maricas... de cualquiera con un problema anormal” (2006: 150) y, finalmente, cómo engañó al equipo terapéutico con un relato biográfico que, entre otras cuestiones, ocultaba la toma de hormonas esteroides. A partir de este caso, Garfinkel nos recuerda la común aspiración de ser reconocidos socialmente como sujetos adultos competentes y normales. La consideración de Agnes como sujeto adulto competente pasaba, entonces, por apartarse de la contaminación que suponía la homosexualidad y conseguir la transformación hormono-quirúrgica de su cuerpo para que su identidad como mujer -biológicamente había nacido macho y había vivido un tiempo como varón-fuera autorizada.
} 
reclamaban palabras no médico-dependientes tales como gays o lesbianas. En esta resistencia a la explicación médica de su existencia, una de las prioridades políticas del movimiento gay/lésbico durante la década de los pasados años setenta fue extraer el diagnóstico homosexualidad del catálogo de psicopatologías. El movimiento gay/lésbico intentaba generar un discurso propio que sustituyera el «discurso de las instancias del control social» (Guasch, 2000: 92) y, en este sentido, cobró especial relevancia combatir el estigma asociado a la condición patológica. Tal objetivo fue alcanzado cuando la homosexualidad fue descatalogada como enfermedad mental por las Asociaciones Americanas de Psicología y de Psiquiatría -antes por la primera que por la segunda- en la década de los setenta ${ }^{9}$. Casi de forma paralela, la transexualidad entraba codificada como enfermedad en la Clasificación Internacional de Enfermedades en el año 1977 y, poco después, lo hacía en el manual más extendido entre psicólogos y psiquiatras para construir sus diagnósticos (DSM-III, 1980).

Así, mientras gays y lesbianas recorrieron un camino hacia el estatus de sano, la población transexual asumió el discurso de la enfermedad como un instrumento que ayudaba a alejarla en el imaginario social de las ideas de perversión y vicio. Además, como hecho diferencial de gays y lesbianas, la población transexual reclamaba cada vez con mayor fuerza el abordaje terapéutico centrado en su transformación corporal. En este sentido, la petición de hormonación y cirugía cobraba mayor fuerza si se hacía depender de la necesidad de corregir una situación patológica, aunque los científicos biologicistas aún no supieran explicar si como alteración cromosómica, si como alteración hormonal (Benjamin, 1966). En cualquier caso, este argumento parecía tener una mejor perspectiva para combatir el rechazo social. Por último, en relación con esta idea, el discurso de la enfermedad pareció imprescindible para que las asociaciones transexuales pudieran argumentar su petición de que tanto los sistemas nacionales de salud como las pólizas privadas de asistencia sanitaria cubrieran los elevados gastos del proceso transexualizador: psicólogos, psiquiatras, endocrinólogos, cirujanos plásticos, urólogos, ginecólogos, analistas clínicos, incluso foniatras, logopedas y especialistas en medicina estética.

En esta misma línea, como ya adelantábamos, las organizaciones transexuales surgidas en el Estado español desde finales de la década de los ochenta centraron buena parte de sus reivindicaciones en la inclusión del tratamiento transexualizador dentro de los servicios sanitarios públicos (Ramos, 2003) y entendieron el itinerario terapéutico

9. La Organización Mundial de la Salud retiró la homosexualidad de su taxonomía diagnóstica el 17 de mayo del año 1990. Ese día ha sido designado como el Día Internacional de Lucha contra la Homofobia y la Transfobia, dato significativo para los intereses de este texto. No se nos escapa que la explicación patológica de la transexualidad es incluida, desde esta perspectiva, como un ejemplo de la respuesta social transfóbica. 
médico-dependiente como la salida más viable para que muchas de las personas a las que representaban alcanzaran el estatus de persona normal. Sin embargo, a lo largo de los últimos años se han observado algunos cambios significativos: buena parte de las líderes del movimiento asociativo transexual -a partir de ahora MAT- en nuestro país, de idéntica manera a lo ocurrido en Estados Unidos, comparte un discurso que, alejado de la explicación médica, persigue dar cuenta de sus variadas y en absoluto patológicas formas trans de ser y de estar en el mundo.

La emergencia de este discurso político para el caso español mantiene un decalaje de al menos dos décadas en comparación con Estados Unidos, a tenor de la documentación aportada por el antropólogo José Antonio Nieto (1998) sobre la evolución de la población transexual estadounidense que deviene comunidad transgenérica no médicodependiente. Durante los años ochenta, en la comunidad trans estadounidense -y uso trans para incluir un variado conjunto de experiencias que rebasan el modelo médico y discuten la homología entre sexo y género- se inició un debate sobre si los tratamientos médicos eran la respuesta más adecuada para resolver su cuestión identitaria. Surgieron voces trans que, por un lado, reclamaron sus genitales de nacimiento como órganos que no les molestaban y de los que no deseaban desprenderse y, por otro lado, denunciaron que sus genitales provocaban molestia social y que, en este sentido, su amputación tributaba a la paz y tranquilidad sociales. Esta nueva perspectiva nos invita a revisar la anterior idea de que la transformación genital -y sexuada en general- de las personas transexuales era una necesidad individual ajena a los patrones normativos (Szasz, 1994: 7), y la vía para conseguir la felicidad de el/la paciente, tal y como se había planteado en el mundo social de Harry Benjamin (1966), uno de los fundadores del modelo clínico de transexualidad.

Este nuevo giro de la interpretación emic de lo que para la psiquiatría era un trastorno identitario, una interpretación crítica con el clásico itinerario terapéutico a transitar obligatoriamente si se aspiraba al reconocimiento legal de la identidad de género, discurre paralelo al interesante debate intelectual que desemboca en la elaboración de «un vasto cuerpo conceptual alternativo a la visión medicalizada de la identidad de género» (Vázquez, 1999: 38). Para todo ello podemos destacar, sin intención ni capacidad de exhaustividad, la repercusión de la obra de Michel Foucault interesado por el proceso de medicalización de las sociedades occidentales (1990) y por la psiquiatrización del placer perverso como un dispositivo de saber-poder (1998a); a las investigadoras feministas que, como las antropólogas Martin y Voorhies nos muestran contextos culturales con sexos y géneros «supernumerarios»-que rebasan el número de dos- y dan cuenta de «una nueva posibilidad de perspectiva sobre el fenómeno de la identidad sexual» (1978: 82); a los trabajos de apóstatas de la psiquiatría como Thomas Szasz (1976) que cuestiona la cientificidad de los diagnósticos psiquiátricos; al psiquiatra, con formación antropológica, Arthur Kleinman (1980), que define a la biomedicina como un sistema 
cultural sujeto al análisis antropológico y que, por lo tanto, permite estudiarla como «una etnomedicina más aunque fisiológicamente orientada» (Comelles y Martínez, 1993: 57); y, por último, a una variedad de estudios aportados desde la teoría social, la historia, los estudios gays/lésbicos/queer, incluso desde las mismas entrañas de la Biología con autoras feministas como Anne Fausto-Sterling (1993) que revisa nuestro modelo dicotómico macho/hembra y propone la existencia de, al menos, cinco sexos.

Este vasto conjunto de pensamientos críticos ha calado de lleno en líderes del MAT español: andaluzas como Kim Pérez y Carla Jiménez, y no andaluzas como Juana Ramos, Yliana Sánchez y Natalia Parés. Muchas de ellas comparten su formación universitaria -filósofa, ingeniera, economista-, su prolongada experiencia en el ámbito asociativo, su lectura de bibliografía antropológica y sociológica -crítica con la terapéutica y explicación médicas del fenómeno transexual-, sus vínculos con asociaciones transexuales de otros estados y sus contactos con el movimiento feminista y de gays, lesbianas y bisexuales. Estos factores intervienen para la construcción de un discurso teórico emic, cada vez más alejado de la referencia a la enfermedad aunque sin descartar la explicación biológica -defendida por autores como Zhou et als (1995)- sobre la discordancia entre cuerpo sexuado e identidad de género.

Las manifestaciones de Juana Ramos, Yliana Sánchez y Carla Jiménez, por ejemplo, informan sobre su crítica a los rígidos modelos de género de nuestro mundo cultural, incapaz de admitir ni la existencia de más de dos sexos ni la posibilidad de un continuum del género que nos ayude a mirar más allá de la polarización.

[...] Aunque no quieras, tienes que elegir entre ser hombre o ser mujer [...] En nuestra sociedad hay dos grupos en el tema de los géneros. Podría haber más, pero hay dos grupos: el grupo de los hombres y el grupo de las mujeres (Juana Ramos).

De forma que no me siento un hombre, ¿entonces qué soy? [En nuestro sistema dicotómico, la única respuesta socialmente autorizada es: mujer] (Yliana Sánchez).

[...] Yo creo que si los demás fueran más tolerantes, y si no existiera ese estereotipo de hombre y mujer tan definido y tan marcado, no tendríamos tantos problemas (Carla Jiménez).

Frente a quienes aún hablan de los tratamientos hormono-quirúrgicos a los que la población transexual se somete como una preciosa demostración de nuestro ascenso civilizatorio, algunas voces trans nos hacen dar de bruces con tal interpretación. En efecto, las palabras de Bianca y Julio nos ayudan a ver que, cuando se trata de argumentar los motivos de la cirugía de reasignación sexual -a partir de ahora CRS-, el discurso del libre albedrió oculta una presión social que conviene desvelar. 
La sociedad no quiere tener maricones con tetas y polla, quiere tener mujeres para que encaje todo, ¿entiendes? (Declaraciones de Bianca Fox, en Pierrot 2006: 94).

Nadie debe obligar o condicionar a las personas transexuales para que se operen. Cada transexual debe ser quien decida si debe operarse o no debe operarse. Sin embargo, observamos cómo el sistema fuerza a la operación. Operarse para que el forense dictamine que sí puede cambiar el nombre. Entonces, se está forzando el cambio de sexo (Julio, militante de Lambda, Valencia) ${ }^{10}$.

Estas voces están recogidas antes de que la conocida como Ley de Identidad de Género, aprobada por el Parlamento español durante el año 2007, posibilitara el reconocimiento legal de la identidad como varón o como mujer sin la necesidad de tributar los genitales en el altar quirúrgico. Hasta ese momento, si la persona transexual demandaba este reconocimiento legal, el juez podía solicitar un certificado del profesional autor de la cirugía (CRS) o bien requería un peritaje profesional. En este último caso, el experto científico-sexuador era un médico forense que inspeccionaba la conformación de los genitales externos de el/la demandante y, en función de lo observado, sancionaba la condición de macho fenotípico - ergo varón- o hembra fenotípica -ergo mujer. Los dos tipos de actuaciones se ilustran con sendos ejemplos en los que el juez, en el primer caso, solo valora la documentación presentada por la demandante y, en el segundo, solicita la intervención de un forense para examinar a el demandante.

Caso A. En mi caso fue todo muy suave porque por la experiencia de [nombre de mujer], yo sabía que convenía hacerlo de la manera más rápida posible. Es decir, no sobrecargar al juez con pruebas sino, a ser posible, presentar el certificado de operación y santas pascuas. Y que él pregunte si acaso. Entonces lo hice así. El juez preguntó algunas cosas. Tuve una entrevista con él; también me pidió que llevara a testigos. Los testigos eran amigos míos que dijeron que, efectivamente, vivía como mujer y todo esto. Se notaba que el pobre no sabía muy bien qué preguntar. Me dio el cambio de sexo al cabo de seis meses, lo cual no es demasiado. [El juez] me pidió el certificado de que me había operado. No me vio el forense (Débora, Granada).

\footnotetext{
10. Sobre la cuestión que plantea este informante, se hace necesaria una aclaración. En realidad no era el forense quien dictaminaba si se podía o no cambiar de nombre. Existía la posibilidad de realizar este cambio, vía judicial, sin otros requisitos que disponer del dinero suficiente para sufragar los gastos derivados y elegir un nombre ambiguo -como Rosario, Trinidad o Reyes, entre otros- incluido en un listado disponible en el Registro Civil y que no implicara confusión en relación con la identidad de género demandada (Bustos, 2008).
} 
Caso B. Acudí al Juzgado, muy bien vestido, con traje de chaqueta y con barba. El forense me dijo que me bajara los pantalones. Yo creo que se quedó un poco extrañado por la cara que puso. Tengo un pene pequeñito [se sometió a una metaidoplastia -construcción quirúrgica de un falo a partir del clítoris- y a la inserción de dos prótesis testiculares], pero desde luego no tenía una vagina. El forense me dijo que me subiera los pantalones y certificó que yo era un hombre (Pedro, Madrid).

Las anteriores voces transexuales, vinculadas en su mayoría al MAT, están mostrando un cambio radical en el análisis emic del fenómeno que nos ocupa. Desprendiéndose de la categoría cuerpo equivocado y de su uso como sustrato material sobre el que efectuar múltiples intervenciones quirúrgicas transformadoras para construir el cuerpo verdadero que demanda el orden social, algunas académicas y transactivistas como Gordene Mackenzie (1994) plantean trasladar la discusión y la batalla política desde el campo de un "cuerpo erróneo" hasta el campo de haber nacido en una sociedad/cultura "errónea" (Nieto, 1998: 24-25). Con esta misma mirada, transactivistas españolas explican el problema transexual como una construcción cultural, una consecuencia de nuestro propio sistema de sexo-género:

Bajo mi punto de vista las personas transexuales somos víctimas y resultado de este sistema esclavizante de los sexos-géneros (Ramos, 2004: 87).

La norma sexual basada en una concepción dicotómica de los sexos y géneros ha empujado a las personas trans (de igual forma que al resto de personas) hacia dos y solo dos modelos a reproducir para adaptarse al sistema social. Los avances tecnológicos en el ámbito de la medicina han hecho posible modificar la propia morfología sexual para contribuir a este proceso de adaptación a los modelos establecidos de cuerpos sexuados (Juana Ramos, 2009).

Seguramente no es que mi naturaleza esté equivocada, sino que la sociedad en la que he nacido está equivocada (Yliana Sánchez, notas de campo)

Es precisamente en este debate que se desliza hacia la despatologización de la experiencia trans donde la antropología, con la precaución de no caer en la tramposa idea de la universalidad de la transexualidad, puede aportar decenas de ejemplos etnográficos de transgresiones del sexo por el género, de variadas posibilidades culturales para trascender la identidad de género asignada al nacimiento que no requieren intervenciones hormonoquirúrgicas (Martin y Voorhies, 1978; Cardin, 1984; Mathieu, 1991; Ramet, 1996; Bolin, 1996; Nieto, 1998; Nanda, 2000). De hecho, de forma tan escueta como contundente, José Antonio Nieto escribe que "para el xanith, el mahu o el kathoey la anatomía nunca fue destino" (1998: 32-33), lo que viene a recordarnos la necesidad de contextualizar los fenómenos a estudiar en el espacio cultural y en el tiempo histórico sin posibilidad de 
hacer traducciones trans-culturales tan automáticas.

Planteado el fenómeno transexual en estos términos; a saber, como un cuerpo verdadero en una cultura equivocada -y violenta con aquellas diferencias que dota de especial significado contaminante-, los conflictos para muchas personas transexuales y, también, dentro del MAT, están abonados. Así, el debate sobre si las personas transexuales son o no son enfermas, se ha reabierto de forma intermitente en el seno de las asociaciones y se observó con gran vehemencia en nuestro país justo cuando se discutían los contenidos de la conocida como Ley de Identidad de Género 3/2007.

\subsection{DEBATES TRANS SOBRE LA ENFERMEDAD. TENSIONES, CONFLICTOS Y PARADOJAS}

Para ilustrar lo anteriormente descrito, haré referencia a algunos debates -transcritos como notas a mi diario de campo-, en el seno de varios encuentros y reuniones trans celebrados en distintas ciudades españolas, generadas al hilo de la necesidad o no de someterse a la CRS. Por último, presentaré sendos comunicados de las asociaciones Asociación Transexual Española-A.E.T.-Transexualia (AET, Madrid) y el Collectiú de Transsexuals de Catalunya-Pro Derechos (CTC, Barcelona) donde, en primer lugar, exponían su postura respecto a esta cuestión y, en segundo lugar, contenían buena parte de las reivindicaciones más tarde recogidas por el movimiento por la despatologización de las transidentidades en nuestro país.

Durante la celebración de los I Encuentros Estatales Mixtos de Transexuales celebrados en Valencia durante el año 2002, uno de entre los varios a los que asistí durante mi trabajo de campo, una transmujer, con un discurso especialmente beligerante hacia la visión médica de la transexualidad y poco común entre la población que hasta entonces había conocido, intervino durante uno de los tiempos de coloquio. Su edad rondaría los cuarenta años. Llevaba una falda de volantes y una camisa sobre la que se superponía un chaleco indio sin mangas, de colores brillantes y algunas lentejuelas; todo conjuntado con unas botas militares y un pañuelo palestino anudado al cuello. Su timbre y tono de voz no eran de los que yo estaba acostumbrado a escuchar porque, hasta entonces, había observado que muchas mujeres transexuales utilizaban una técnica para agudizarla. Esta participante se presentó como una anarquista, militante en varios movimientos sociales, y planteó de forma vehemente su oposición a que el discurso transexual común girara en torno a "tener o no tener" unos determinados genitales. Su planteamiento principal era que, mientras muchas de sus compañeras eran una reproducción de los estereotipos al uso sobre la mujer - un planteamiento en el que coinciden aunque con sus distintas explicaciones, militantes feministas (Raymond, 1980; Garaizábal, 1998), psicólogas y psiquiatras (Millot, 1986; Chiland, 1999) e incluso reputadas militantes y autoras 
transexuales (Stone, 1991; Cambasani, 2003) ${ }^{11}$-, ella consideraba necesario que un mayor número de mujeres transexuales los rechazaran. Y compartía con otras personas transexuales la lucha contra los dos poderosos tentáculos de este mito tan común: una persona, si no se opera, ni puede ser feliz ni es transexual. Con un tono enérgico y una voz tan grave como ronca, exclamó que ella se sentía mujer, que tenía pene y que no tenía ninguna necesidad de tener una vagina.

En la sala había otras dos mujeres transexuales que pidieron turno de palabra. Y opinaron en la misma línea de la intervención de su compañera. Las dos llevaban peluca, faldas estrechas y botas altas de cuero. Ambas nos comunicaron su condición de mujeres transexuales lesbianas - un dato a todas luces disruptivo con la imagen heteronormativa, la más extendida sobre la mujer transexual- y, añadieron, formaban una pareja estable. No existía para ellas, en aquel momento, ninguna necesidad de transformar sus genitales y exigían al gobierno español la aprobación de una ley que permitiera el cambio de sexo legal "sin necesidad de pasar por el quirófano" -exclamaba una de ellas.

Sentada delante de mí había otra mujer transexual, Lucy, a la que describí en mi diario de campo como representante de la feminidad más idealizada en el pensamiento común. Lucy era una admiradora de lo que denominaba "las bellezas" que aparecían en la web de Carla Antonelli; un modelo de mujer al que ella aspiraba. En un momento del debate, sabiendo que yo era antropólogo y el motivo de mi asistencia, volvió su cabeza hacia mi asiento y con su pregunta marcó los límites de su concepto de transexualidad:

\section{No sé... ¿Tú crees que son transexuales?}

Fue entonces cuando un joven hombre transexual pidió al moderador de la mesa que le concediera el turno de palabra. Con lágrimas en los ojos y la voz entrecortada se dirigió a toda la sala y, en especial, a las tres mujeres trans que anteriormente habían denunciado que las presiones sociales explicaban, por ejemplo, el interminable recorrido

11. Despues de presentar algunos relatos autobiográficos de mujeres transexuales publicados en Gran Bretaña y Estados Unidos y, tras observar que las cuatro mujeres seleccionadas (LilliElbe, Heddy Jo Star, Christine Jorgensen y Canary Conn) reproducen los estereotipos de género sin mostrar ambigüedad alguna, Sandy Stone concluye: "No me extraña que las pensadoras feministas tuvieran sus sospechas. Cómo no, yo también" (1991: 10). Para el caso de una autora transexual española como Olga Cambasani, su planteamiento es que «la mimesis social de la persona transexual dependerá en gran medida de la configuración de los colectivos de género "disponibles" en cada momento histórico, y me temo que ahí no hay sorpresas" (2003: 88). Por supuesto, las transmujeres tienen todo el derecho del mundo a reproducir estereotipos y restablecer la homología entre el sexo y el género, tal y como explica Mathieu (1991). Lo único que señalamos es la dificultad para poder adjetivar, si esto es así, tal experiencia como transgresora. 
poliquirúrgico de muchas de sus compañeras:

Yo lo entiendo. Bueno, entiendo que vosotras no queráis operaros, por lo que sea. ¡Pero por favor, por favor! ¡Yo no puedo vivir así! ¡Yo no puedo vivir más con este cuerpo! ¡Mi única esperanza es la operación! ¡De verdad, es que si decís eso, pues yo no sé qué va a ser!

En otra ocasión, durante una de las reuniones mantenidas en una asociación transexual, se había generado el debate cuando la moderadora requirió nuestras opiniones sobre si la transexualidad era una enfermedad o, por el contrario, era una opción más dentro de las posibilidades del ser humano.

Yo no pienso que la transexualidad sea una opción -dijo una asistente. Una opción es irse a Turquía un fin de semana.

Este mismo debate surgió mientras participaba en un grupo de trabajo que, convocado por una asociación GLTB andaluza, tenía la tarea de confeccionar un texto divulgativo sobre la transexualidad. La redacción del texto había quedado atascada en un punto central para los intereses de este artículo. Había un párrafo significativamente comprometido cuando hablaba de la transexualidad como "un trastorno", expresión sobre la que los autores de ese epígrafe -dos mujeres transexuales y el presidente de la asociación-no habían llegado a un acuerdo tras varias horas de trabajo. La propuesta para solucionar tal atasco era ampliar el debate al resto del grupo. Cuando se me pidió opinión, decidí aportar una alternativa sobre la que discutir: en vez de "la transexualidad es un trastorno", podíamos escribir que "la transexualidad es pensada en nuestra cultura como un trastorno." Pipi, una transexual de unos cincuenta años, no estaba de acuerdo:

Yo sí creo conveniente que [el texto] diga que es un trastorno; que quede muy claro que necesitamos que la Seguridad Social pague los tratamientos porque si no...

Marta, mujer transexual y psicóloga de formación, se unió a la tesis de Pipi y pensaba que lo más conveniente era afirmar en el texto, y sin vacilaciones, que la transexualidad era un trastorno:

Si no ponemos que es un trastorno parece que lo que decimos no tiene nada que ver con nosotras sino que está fuera, que nos catalogan así pero que nosotras no somos así. Y eso no es verdad.

Finalmente pudo ser consensuada una forma de redacción que intentaba recoger todas 
las observaciones y salvar los miedos a que el texto pudiera ser utilizado por quienes aún criticaban la inclusión de los tratamientos transexualizadores en la cartera de servicios del Servicio Andaluz de Salud:

"En realidad, la transexualidad se concibe como un trastorno que, en numerosas ocasiones, requiere la intervención clínica”.

La cuestión sobre la obligatoriedad de la CRS generó un intenso debate en el ámbito del asociacionismo transexual cuando, en noticia recogida por Europa Press el 22 de septiembre de 2003, una asociación llamada Transexualidad Clínica (Madrid) -aunque nunca supimos dónde se reunían ni quiénes la componían- realizaba un llamamiento a toda la población transexual residente en nuestro país -que estimaba en unas 3.000 personas- para que iniciara inmediatamente una huelga de hambre "con carácter indefinido" y lo declarara públicamente hasta que la Ley de Identidad de Género fuera aprobada. Dicha asociación reivindicaba la inmediata consideración del tratamiento transexualizador con cargo a los fondos públicos y las medidas legislativas necesarias para que, posteriormente, los cambios de nombre y de sexo en el registro civil estuvieran asegurados. Esta postura reforzaba el modelo clínico porque hacía depender tales rectificaciones de la comprobación legal de un hecho: el o la demandante debía poseer los genitales acordes a su identidad de género. Y esto significa, ni más ni menos, la obligatoriedad de -y no la libertad de elegir sobre- la CRS.

El comunicado de Transexualidad Clínica provocó la rápida reacción de varias asociaciones que se manifestaron públicamente en su contra. Destacaré las respuestas del Colectiú de Transsexuals de Catalunya (Barcelona) y de la A.T.E.-Transexualia (Madrid). El colectivo catalán publicó un texto rotundo y, desde mi punto de vista, especialmente novedoso en su formulación. Y lo era porque dicha asociación llegaba a comparar la obligatoriedad de la CRS con la ablación del clítoris - una ley ablacionista, afirmaba, refiriéndose al borrador de la Ley de Identidad de Género-, una posición que situaba el debate asociativo -impensable hasta entonces- lejos de la arena de "lo biológico" para acercarlo a la arena de "lo cultural."

La asociación A.E.T.-Transexualia también emitió el correspondiente comunicado donde, tras oponerse a la acción de la huelga de hambre, dejaba clara su posición en relación con la obligatoriedad de los tratamientos quirúrgicos -las negritas son mías:

- [...] creemos que las enmiendas que mejoraban el texto inicial (con el que disentimos en algunos puntos, como la imposición de las operaciones genitales para acceder al cambio de sexo legal), como las de IU, IC-V, ERC, etc, no serían aprobadas [...].

- [...]Apoyamos la protesta del CTC con particulares matices diferentes: 1) No consideramos ablaciones ni castraciones a las intervenciones de genitales, siempre que la persona que se somete a ellas lo haga sin presión, ni imposición alguna. No nos parece adecuado instrumentalizar la lucha contra la ablación 
del clitoris para argumentar y dar fuerza a nuestras reivindicaciones. [...]3) La C.R.S. no debe ser un requisito para poder acceder al cambio de nombre y sexo legal, ya que las técnicas no están muy logradas, especialmente en el caso de transexuales $\mathrm{MaH}$ [mujer a hombre] y el someterse a tal intervención es un asunto muy serio, e íntimo, y no debe estar sujeto a presiones. [...] Consideramos que el sexo psico-social debe prevalecer sobre el genital. [...] 4) Para terminar consideramos el derecho al propio cuerpo como fundamental e inviolable (y sobre todo sin injerencias del Estado y Administraciones), y reivindicamos una Ley que posibilite el cambio de sexo y nombre legal, desde el momento mismo en que se inicia el proceso de cambio, sin tener que haber pasado por la C.R.S. [... 5) Entendemos que el sexo-género de las personas debe perder la importancia que tiene actualmente, pasando a ser considerado un aspecto secundario más de la persona, sin que tenga que estar presente en el DNI, ni documentos similares. Saludos Junta Directiva de AET-Transexualia Madrid, 25 de septiembre, 2003.

El C.T.C. publicó un segundo texto, si cabe más contundente que el primero, donde encontramos antecedentes de una de las reivindicaciones centrales del MAT español durante los últimos años. En un comunicado fechado el día 30 de septiembre del año 2003 se nos informaba que el C.T.C. había dirigido peticiones a diferentes instituciones para conseguir que la transexualidad dejara de ser considerada una patología psiquiátrica. La idea de la construcción cultural de la enfermedad tomaba consistencia: para el C.T.C., el sufrimiento de la persona transexual no dependía de ninguna condición patológica sino de "una sociedad transfóbica" que la incluía en la categoría cultural de "anormal" y, no menos importante, era un error plantear que la demanda de tratamiento transexualizador dependía de la voluntad y libre albedrío cuando, en realidad, "los patrones sociales" estaban actuando para que no existiera otra salida viable - por autorizada- más que la cirugía.

El CTC reunido para tratar este tema y consciente de las implicaciones que conlleva su decisión ha decidido solicitar de las instituciones médicas internacionales, tanto públicas como profesionales, la desclasificación de la Transexualidad como trastorno o enfermedad psiquiátrica. [...] El transexual es una persona como cualquier otra $y$ sus conflictos no provienen propiamente de su identidad, sino de una sociedad transfóbica, cargada de complejos y represiones que pretende aniquilarlo. No es por tanto la transexualidad enfermedad alguna, como nadie es enfermo por ser como es; se trata de una identidad, muy variada en matices, pero que se materializa y uniformiza ante la represión de la sociedad sexista que delimita su contorno y naturaleza.

Si un trans sufre por la crueldad social que experimenta, si enloquece víctima 
de la incomprensión y los malos tratos, ello no implica enfermedad o locura alguna. Si la personalidad sexual del transexual inmerso en una sociedad sexista demanda atención médica transexualizadora, ello no es inherente a la transexualidad, sino que es el fruto de los patrones sociales con que debe vivir el transexual.[...] Es hora de que la sociedad médica rectifique y se enmiende de sus errores, restableciendo la naturaleza e identidad transexual al lugar de dignidad que legítimamente le corresponde, desterrando de su formulaciones cualquier prejuicio y planteamiento transfóbico [las negritas son mías] (CTC, 2003).

De los anteriores comunicados no debemos concluir que sendas asociaciones firmantes se opusieran a la CRS. Nada más lejos de sus intenciones -y de la mía- puesto que entendían que para un número elevado de transexuales, la solución "vital" si se deseaba la autorización legal de la identidad de género, pasaba irremediablemente por esta intervención quirúrgica.

En todo caso, el planteamiento de ambas asociaciones iba en dos direcciones. En primer lugar, en relación con la consideración de la transexualidad como una enfermedad, se comienza a construir un discurso que pretende desprenderse de tal estigma. Así, comienzan a advertir que el sufrimiento no deviene de su naturaleza -sino de la crueldad social-, ni existe alteración enfermiza en su identidad sino que, por el contrario, es la transfobia, como respuesta social negativa y violenta, la enfermedad a tratar y la causa del sufrimiento. El análisis se desplaza desde la patologización del individuo hacia la patologización de lo social. En segundo lugar, en relación con la solución terapéutica, la atención médica transexualizadora, denunciaban que el reconocimiento legal de la identidad de género no podía depender de la marca genital porque, si esto era así, la población transexual estaba siendo presionada para tomar un camino médicodependiente.

La situación hasta aquí presentada no solo muestra las dificultades de aglutinar en un mismo movimiento trans a personas con intereses tan diferentes en el sentido de que quienes asumen el modelo médico y quienes lo rechazan participan de dos formas diferentes de relacionar el sexo y el género -véase Mathieu (1991). También nos señala cómo desde el ámbito asociativo transexual se comienzan a analizar las consecuencias de asumir la explicación médica para alcanzar el reconocimiento de la identidad de género. De construir su subjetividad con los contenidos y tecnologías aportados por las disciplinas biomédicas, la población transexual -como ya hizo el movimiento gay/ lésbico- comienza a elaborar su propio discurso que, ahora, pretende desembarazarse de quienes se habían constituido tradicionalmente como los controladores privilegiados de sus cuerpos (Bolin, 1994). En este sentido, Kim Pérez, líder histórica del MAT andaluz, negociadora con las instituciones para la inclusión del tratamiento transexualizador en 
la cartera de servicios del sistema sanitario público de Andalucía, elabora una crítica a la posición protagonista de la disciplina médica e invita a pensar en un nuevo marco de asistencia en el que los profesionales -médicos y psicólogos- no ostenten el poder para decidir sobre asuntos tan importantes en la vida de muchas personas.

\section{DE LA AUTORIZACIÓN MÉDICA A LA CERTIFICACIÓN. UNA PROPÙESTA TRANS}

Este discurso transexual, elaborado "desde dentro" para enfrentarse a "los intentos médicos de tutela de las decisiones transexuales" - me contaba Kim- y con el objetivo de avanzar en el proceso de "descolonización del cuerpo transexual" (Ayllón, 2004: 24), tiene una buena representante en la ya nombrada Kim Pérez, profesora granadina jubilada, a la que he escuchado en varias conferencias, he leído varias de sus publicaciones y he entrevistado con interés y admiración:

La experiencia transexual, lo cual se vive desde dentro, es completamente diferente de las pautas médicas o psicológicas hechas desde fuera.[...] En estos momentos estamos contemplando la emergencia de un discurso transexual propio que no consiente en ser sustituido por el discurso médico o psicológico. Existe incluso una tendencia a desmedicalizar la transexualidad, como en su día ocurrió con la homosexualidad; despsiquiatrizarla y, en general, a explicar autónomamente nuestros motivos y la toma de nuestras decisiones (2004, entrevista personal).

Cuando en la introducción de este artículo hablaba del proceso de medicalización de las transgresiones de género, ya adelantaba la idea de que las experiencias que contravenían el orden de una sociedad preocupada obsesivamente por definir la normalidad de las características en cada grupo social de género, de las relaciones sociales entre los géneros y, por último, de las prácticas sexuales, fueron construidas por la medicina como experiencias patológicas. $\mathrm{Y}$ en función del positivismo biologicista que ya se imponía, tales experiencias patológicas requerían ser explicadas en función de un marcador biológico a descubrir. Sin embargo, pese a que la comunidad científica no había acordado la existencia de marcador biológico, pese a que se había cuestionado la conveniencia de aplicar una terapéutica centrada en la administración de hormonas esteroides y la CRS (Billings y Urbans, 1982; Hausman, 1992; Chiland, 1999), la transexualidad se incorporó a la taxonomía de enfermedades psiquiátricas (DSM-III, 1980) y, al menos desde finales de los años veinte, algunas personas estaban siendo sometidas a terapias corporales transexualizadoras con resultados tan dramáticos como la muerte de Lilli Elbe en la mesa de operaciones cuando se sometía a su tercera cirugía (Hausman, 1998: 194). Esta paradoja, propongo, la de que las cirugías se realicen antes de que la medicina pueda ofrecer un diagnóstico y una explicación del fenómeno, solo se resuelve si no perdemos 
de vista que la funcionalidad social del tratamiento es anterior a su objetividad científica. Y para una segunda cuestión no es menos importante recordar tanto a Foucault cuando escribía que "el control de la sociedad sobre los individuos no se opera simplemente por la conciencia o por la ideología sino que se ejerce en el cuerpo, con el cuerpo" (1977: 5); como a la socióloga feminista Colette Guillaumin cuando nos recordaba que "el cuerpo es el primer indicador del sexo" y que éste siempre parece advertirse socialmente con la necesidad de que sea "cuerpo sexuado" (1992:1). Con este encuadre propongo entender la paradoja terapéutica del modelo clínico de transexualidad que tan poco aborda lo psíquico y tan ampliamente aborda lo corporal; pero que tan funcional resulta para borrar los cuerpos que cuestionan no solo el orden dicotómico sino nuestra lógica identitaria hegemónica caracterizada por la relación homológica entre sexo y género. Señaladas estas paradojas reveladoras, tanto como su resolución "científica", no es menos importante destacar que al reservarse el derecho al diagnóstico, la medicina también reservaba su derecho a decidir cuáles eran las tecnologías de género aplicables. Y a quién. Para tal fin, diversos autores fueron construyendo los criterios diagnósticos después reconvertidos en criterios para elegir y disponer quiénes sí y quiénes no tenían la autorización para continuar los tratamientos hormonales y quirúrgicos (Tena, 2010). Las consecuencias fueron importantes: las decisiones de la población transexual, ahora población de pacientes que debía asumir la autoridad experta, quedaban supeditadas a la aprobación de esta última. Para ello, además, las personas que aspiraban al diagnóstico de transexualidad, en una relación clínica claramente asimétrica, tenían que asumir su condición de enfermas psiquiátricas. Las palabras de Soledad, una joven transexual andaluza vinculada a varias asociaciones G.L.T.B., son clarificadoras al respecto:

Nosotras tenemos que pasar por insanas mentalmente.

Todo lo anterior ha sido motivo de reflexión y análisis por parte de autoras y transactivistas como Kim Pérez. Aunque ella no pretende restar competencias a los médicos en campos como la prescripción y evaluación de los tratamientos farmacológicos con hormonas esteroides, lo que sí critica es el poder de los médicos -y psicólogos- para decidir si una persona es o no es transexual.

[...] al médico no se le puede conceder el derecho a decir si tú eres transexual o no porque, entre otras cosas, el diagnóstico supuesto no está establecido en ninguna parte; no existe ninguna unanimidad de criterios respecto a qué es una persona transexual y, finalmente, es una decisión personal y completamente inverificable por otra persona. Es una decisión personal de la cual, puesto que la persona está en condiciones de asumir la responsabilidad sobre sus hechos, en ese momento, se le debe conceder esa responsabilidad. Incluso el derecho a equivocarse [...] Lo que los 
médicos han hecho es asumir unos poderes sociales que no le corresponden.

Acostumbrada a lidiar con proyectos tan complicados como conseguir la financiación del tratamiento transexualizador por parte del Servicio Andaluz de Salud, a tener que negociar con diversos agentes sociales cuando ha reclamado sin descanso los derechos de la población transexual, Kim me hacía partícipe de una fórmula elegante para defender que aquélla tome las riendas de sus decisiones y de sus vidas.

En los últimos años, los transexuales, agradeciendo los esfuerzos de comprensión de los médicos, intentamos sacudirnos por todos los medios de la tutela médica.

"Sacudirse de la tutela médica", sin intención ni de demonizar ni de desprestigiar a la medicina, tiene su traducción política en la propuesta de líderes transexuales que, como la mantenida por Kim Pérez, continúa la línea observada en otros estados europeos ${ }^{12}$. Kim se opone frontalmente a los protocolos médicos utilizados para la asistencia clínica de la población transexual en los hospitales públicos españoles que han creado unidades ad hoc. Ella denomina protocolos de autorización a esos documentos de actuación clínica que son gestionados por una comisión tripartita formada por psiquiatra o psicólogo, endocrinólogo y cirujano. El procedimiento que sigue esta comisión es, en primer lugar, valorar a el/la paciente para autorizar -o no- su progreso en el itinerario terapéutico a partir de su etiquetado diagnóstico y, en segundo lugar, siempre que se cumplan determinadas condiciones como la de haber iniciado el test de vida real, autorizar los sucesivos tratamientos hormonales y quirúrgicos. Todo ello era necesario para que, antes de la aprobación de la Ley de Identidad de Género 3/2007, finalizada la etapa quirúrgica genital, la sociedad lo reconociera como un hombre o como una mujer a través de la institución del derecho.

Este sistema de autorización lo que hace en el fondo es someter la decisión más importante de nuestras vidas, la que más angustias normalmente nos ha costado, y la que más valor requiere para seguir adelante, [...] a una decisión de expertos que, como se demuestra en todas partes, tienen una idea solamente aproximada de lo que es la transexualidad. Y [...] de las enormes modalidades, variantes, matices, que hay en la transexualidad. La inmensa variedad de posibilidades. Entonces, esto

12. Es el caso del movimiento transexual británico que solicitó la aprobación de una Ley de Identidad de Género que restara autoridad a las decisiones médicas. Por ahora, la Ley Argentina, sancionada el 9 de mayo de 2012, es la única que no patologiza la condición trans pues señala que “[...] en ningún caso será requisito acreditar intervención quirúrgica por reasignación genital total o parcial, ni acreditar terapias hormonales u otro tratamiento psicológico o médico" (Ley 26743). 
resulta, desde un punto de vista humano, y si se quiere a nivel político, inaceptable para las personas transexuales.

La cuestión política que Kim está planteando en estas palabras y de forma tan temprana como el año 2004, junto a otras líderes del MAT español, es conseguir que el anterior modelo de autorización pueda ser sustituido por un nuevo modelo de certificación. En este último caso, el protagonismo no es otorgado al experto sino a la persona que demanda el reconocimiento legal de su identidad de género.

Nosotras proponemos [...] que se debe hacer simplemente un procedimiento en el que se reconozcan hechos, se certifiquen hechos dados sin necesidad de autorizar nada.

Esta alternativa consiste en la posibilidad de que una persona que demanda el reconocimiento de su identidad de género solo necesite algunos certificados de instituciones y profesionales. Kim plantea un modelo de tres certificados: El primero de ellos, que podría ser emitido incluso por los Servicios Sociales del Ayuntamiento de la ciudad donde la persona reside, haría constar -y para ello podía servirse, por ejemplo, de los testimonios de la vecindad- que está viviendo con la identidad de género solicitada. El segundo tendría carácter psiquiátrico pero no para concluir la existencia de un trastorno psiquiátrico -nomínese trastorno de la identidad sexual, transexualidad o disforia de género- sino para afirmar que no existe ninguna psicopatología que potencialmente pudiera alterar su capacidad de decisión, que "la persona está en su juicio para tomar esta decisión" sobre los tratamientos, resume Kim. Y el último certificado haría constar que la persona demandante ha sido informada correctamente sobre el proceso y que, como consecuencia, es autónoma para tomar la decisión que desee sobre su abordaje:

[El tercer certificado] podría emitirlo un psicólogo acerca de que la persona ha recibido información exhaustiva durante también un tiempo predeterminado, un año pongamos, acerca de las consecuencias de sus acciones; ha recibido información acerca de lo que puede significar el cambio físico, sus consecuencias psicológicas, etcétera, y que ha clarificado sus dudas, se han contestado a sus dudas. [...] Al cabo de ese año la decisión está en manos de la persona. Yo ya le he demostrado, por ejemplo, que llevo viviendo equis tiempo con arreglo al sexo deseado, he demostrado que estoy cuerda para tomar las decisiones, he demostrado que he recibido información suficiente de mis actos y ya, en ese momento, la sociedad no tiene más que reconocer que soy un ser libre, que soy un ser autónomo para tomar mis propias decisiones.

Es necesario aquí retomar la idea de que durante varias décadas, un gran número de personas transexuales, fundamentalmente a partir de las propuestas del equipo de 
Hamburger en Europa (1953) y de Benjamin en Estados Unidos (1966), asumieron el modelo clínico de la transformación corporal como la solución vital para intentar ser aceptados en nuestro mundo social como adultos competentes, con más o menos éxito en función de que tal transformación les permitiera alcanzar con éxito el objetivo de "pasar por una mujer" o "pasar por un hombre" (Garfinkel, 1967; Warren, 1993).

Este modelo médico o clínico tenía varios ejes centrales que configuraban los perímetros de la experiencia permitida; a saber, la repugnancia hacia los genitales de nacimiento que explicaba la demanda de eliminarlos quirúrgicamente y construir los correspondientes al género reclamado, la homología entre sexo y género, la condición heterosexual en el género de destino y, finalmente, su deseo por incorporarse a los grupos sociales de género interpretados como verdaderos: los hombres o las mujeres (Benjamin, 1966). Este modelo se podría resumir en el slogan "cuerpo equivocado", una expresión tantas veces repetidas entre la población transexual -y entre el personal de medicina-, sobre el que era necesario aplicar las tecnologías médicas del género para, desde su misma lógica, transformarlo en un "cuerpo verdadero." De este modo, en cuanto completaban el proceso de transformación sexuada, abandonaban la categoría transexual. Y no nos parece menor destacar que de este abandono se derivaban dos cuestiones: en primer lugar, se desactivaba la estabilidad de la participación en un movimiento asociativo y, en segundo lugar, se cercenaba la posibilidad de hacer visible socialmente una posición de sexo-género supernumerario. La posibilidad trans quedaba neutralizada y el sistema dicotómico de sexo-género quedaba a salvo porque, como escribía Nicole Claude Mathieu, el sistema social "intenta reconducir a esos terceros sexos y terceros géneros hacia un pensamiento bicategorizante" $\mathrm{y}$, desde esta perspectiva de análisis, la transexualidad clínica no es una transgresión sino una desviación institucionalizada (1991:299-230). La disciplina médica había impuesto unos determinados límites a las experiencias trans que han estado borrando durante muchos años toda esa variedad y posibilidades a las que tanto Kim Pérez como el comunicado del CTC hacían referencia. Pero en los últimos años hemos observado cómo tales límites han sido traspasados desde múltiples frentes. Así, de un modelo clínico homogeneizador en el que solo parecía tener cabida un perfil transexual como producto representativo de nuestro orden social $-y$ moral- sobre el cuerpo, el género, la práctica sexual y la identidad, se ha pasado a un conjunto diverso de transexualidades. Existe una presencia cada vez más visible de trans que ya no quieren "pasar por" un hombre o "pasar por" una mujer (Warren, 1993) y, por este motivo, politizan la construcción sexuada del cuerpo y reclaman con orgullo su específica condición trans. A ellxs -y utilizo ellxs para ampliar el modelo dicotómico con una fórmula emic-se suman los transhombres con mamas desarrolladas que no desean amputar, y quienes se sienten hombres con vagina sin necesidad de un falo construido; las mujeres transexuales que no requieren intervenciones de mamoplastias, ni cirugías transgenitales; mujeres con pene y testículos. Estas experiencias, que politizan la anatomía, nos han ayudado a 
pensar en una identidad de género que no depende de la marca genital y, por lo tanto, a cuestionar la obligatoriedad de la CRS. También se une la población transdisidente de la heterosexualidad que nos muestra la pluralidad con la que los deseos se manifiestan: hombres transexuales gays, mujeres transexuales lesbianas, hombres y mujeres transexuales bisexuales que, como ilustración del régimen político heterosexual (Wittig, 1992), no fueron contemplados como posibilidad en el DSM-III (1980) (Martínez, 2002; Mejía, 2005). Y la población de transvestistas, de drag-queen y de drag-kings que juegan con las representaciones del género y nos muestran la artificialidad de tal categoría. Y la población transeúnte del género que muestra la flexibilidad, mutabilidad, inestabilidad y artificialidad de las identidades frente al esencialismo biomédico (Nieto, 1998). A ellas, además, hay que sumar la población de personas intersexuales -término que amplía la categoría hermafrodita- ya organizada en asociaciones que denuncian las cirugías a las que fueron sometidas durante su infancia y adolescencia, y las califican de "intervenciones normalizantes, innecesarias, no consentidas y mutilantes" (Cabral, 2012) porque sus cuerpos ambiguos provocan malestar social y, por ello, son borrados quirúrgicamente para negarles la existencia (Kessler, 1990). Sin duda, el eco de su denuncia resuena con fuerza en el discurso crítico con las terapias médicas transexualizadoras.

Todas las experiencias anteriormente señaladas son resistencias y fugas -también señalan caminos para rescatar nuestra autonomía- de las normas sociales que prescriben lo que un hombre y una mujer son y deben ser. Todas ellas escapan al itinerario terapéutico institucionalmente previsto para quienes incumplen la homología entre el sexo y el género; y constituyen, cada una con sus especificidades, itinerarios políticos porque cuestionan los límites impuestos a partir de lo que las disciplinas biomédicas han definido como cuerpos, sexos, géneros, sexualidades e identidades de verdad.

\section{CONCLUSIONES. LO QUE PODEMOS APRENDER DE LA DESPATOLOGÍZACIÓN DEL FENÓMENO TRANSEXUAL}

De la misma manera que acordamos que la construcción de la subjetividad transexual no puede entenderse sino "a través de las relaciones con las instituciones y la tecnología, [y] no solo en el contexto de las relaciones de intersubjetividad" (Hausman, 1998: 198), el movimiento asociativo transexual, en palabras de Juana Ramos, "comenzó también muy ligado a las concepciones clínicas" (2003: 126). Partiendo de esta filiación médica de la identidad transexual, producto de un específico contexto tanto ideológico como tecnológico (Hausman, 1998: 198) durante los últimos años observamos cambios importantes en la relación que la población transexual española -y sobre todo líderes de su movimiento asociativo- mantiene con la disciplina médica. De una interpretación de la medicina como la ciencia que solucionaba su problema vital, se ha pasado a una crítica sobre su papel como terapéutica social; de una interpretación de los tratamientos quirúrgicos como la única salida posible para ser feliz y normalizar sus vidas, se ha 
pasado a reconocer los paralelismos tanto de la CRS con la mutilación genital -aunque comparto con Nieto la limitación de esta comparación (2008)- como de la extirpación de gónadas con aquella corriente eugenésica que impedía la reproducción de los socialmente considerados como no-normales. Y la consideración de un cuerpo que aprisionaba se ha deslizado hacia la consideración de un régimen cultual opresor que borra la posibilidad material de cuerpos disidentes. Este planteamiento está en el núcleo de las declaraciones de algunas transactivistas:

Seguramente no es que mi naturaleza esté equivocada, sino que la sociedad en la que he nacido está equivocada (Yliana Sánchez).

Y ya se deja ver en carteles reivindicativos usados desde el movimiento asociativo transexual para denunciar la transfobia:

"No somos personas atrapadas en un cuerpo equivocado sino personas atrapadas en una sociedad equivocada" (ATA, Asociación de Transexuales de AndalucíaSylvia Rivera).

En general, las distintas asociaciones que defienden los derechos de la población transexual se han ido sumando a una corriente cada vez más visible que problematiza la construcción médico-psiquiátrica de su experiencia para, en cambio, sustituir tal perspectiva por otra que plantea la salud de su condición. Cada vez son más las personas trans que consideran que el estigma de la enfermedad psiquiátrica viene a complicar una situación vital ya suficientemente difícil en muchas esferas de la vida social. Y además de lo anteriormente señalado, la población trans también avanza, frente al hegemónico modelo clínico, hacia la visibilización de un género no necesariamente circunscrito a los estereotipos de la masculinidad y la feminidad y hacia la construcción de un cuerpo que huye de las tradicionales intervenciones médicas.

En relación con esta última cuestión, la solución mostrada por la población transgenerista, aquélla que no necesita invocar la presencia del espíritu quirúrgico para lograr la salvación de sus cuerpos, fue recogida por la Ley 3/2007, de 15 de marzo, reguladora de la rectificación registral de la mención relativa al sexo de las personas. Esta ley ya no contempla la condición necesaria de la cirugía transgenital para conseguir el reconocimiento legal de la identidad de género. Sin embargo, para alcanzar tal reconocimiento, persiste la condición necesaria de un diagnóstico de disforia de género y un tratamiento médico mínimo de dos años "para acomodar sus características físicas a las correspondientes al sexo reclamado" (Bustos, 2008: 335); un tratamiento de acomodación, conviene recordar, que significa superar un test de vida real -una verdadera escuela social del género donde sus estudiantes aceptan las nociones de sentido común sobre el cuerpo, el sexo y el 
género de las que participa el pensamiento común y la definición médica (Tena, 2010: 16) - y someterse a un tratamiento con hormonas esteroides para alcanzar un cuerpo adecuadamente sexuado que no ocasione molestia social. El grado de acomodación de cada paciente se nos revela, entonces, como el criterio evaluador del éxito terapéutico. Una vez que la citada Ley de Identidad ha ayudado a que las personas transexuales se constituyan como sujetos de derechos (Ramos, 2009), se ha extendido un discurso crítico con el modelo médico de transexualidad, al menos en tres aspectos principales: $1^{\circ}$. En la consideración de las identidades disidentes de las asignadas al nacimiento como enfermedades psiquiátricas; $2^{\circ}$. En el régimen terapéutico impuesto para el reconocimiento legal de la identidad de género; $3^{\circ}$. En el poder médico para decidir sobre la veracidad de la identidad de género reclamada. Y este discurso crítico, tal y como hemos mostrado a lo largo del texto, puede ya sondearse en el modelo de certificación propuesto por Kim Pérez, y en los comunicados firmados tanto por la ATE-Transexualia (Madrid) como por el Colectiú de Transsexuals de Catalunya en el año 2003.

La extensión de este discurso crítico, sobre todo entre la generación trans más joven, ha aglutinado al MAT en el Estado español en torno a nuevos objetivos. Así, tras una agenda política en la que, conseguida la despenalización de la CRS en 1983, era urgente la inclusión de los tratamientos médico-quirúrgicos como prestaciones debidas de los distintos sistemas nacional de salud de las Comunidades Autónomas, aquélla deviene ahora dotándose de un contenido en principio paradójico: la lucha contra la patologización que se consolida en el movimiento STOP PATOLOGIZACIÓN TRANS 2012 -abreviado STP 2012- extendido por multitud de países a partir del año 2006. Se trata de una campaña organizada por muchos grupos y activistas de diferentes partes del mundo englobados en la Red Internacional por la Despatologización Trans que intenta recabar todos los apoyos posibles -de científicos, asociaciones de profesionales sanitarios, movimientos sociales e instituciones nacionales y supranacionales- para conseguir que la transexualidad deje de constituir un diagnóstico en las principales clasificaciones de enfermedades, tanto la Clasificación Internacional de Enfermedades como el Manual Diagnóstico y Estadístico de Enfermedades Mentales, cuyas últimas versiones están pendientes de publicación para los años 2013 y 2015, respectivamente.

En esta línea de la despatologización, algunos cambios ya se están produciendo y nos plantean un horizonte de esperanza para que las personas puedan decidir autónomamente sobre su identidad de género, sin tutela médico-psicológica. En primer lugar, el Parlamento Europeo acordó, el pasado 28 de septiembre de 2012, eliminar la consideración patológica de la transexualidad. En esta línea, algunos cambios nominales ya se han producido y, situándonos en Andalucía, la que fue aprobada en 1999 como Unidad de Trastornos de la Identidad de Género (UTIG), ubicada en el Hospital Carlos Haya de Málaga, ahora se denomina Unidad de Transexualidad e Identidad de Género. La antes $\mathrm{T}$ de Trastorno ahora es $\mathrm{T}$ de Transexualidad. En segundo lugar, asociaciones de 
ámbito supranacional que luchan por los derechos de las minorías sexuales, tales como ILGA-Europa, han recogido esta prioridad del movimiento trans por escapar del discurso que los confirma como pacientes psiquiátricos y los obliga a un determinado itinerario terapéutico. Por este motivo, el informe de ILGA-Europa titulado Annual Review of the Human Rights Situation of Lesbian, Gay, Bisexual, Trans and Intersex People in Europa. 2011 evalúa negativamente, para el caso de España, dos cuestiones relacionadas con la autoridad médica de la que depende el cambio registral de la mención de sexo (legal genderrecognition): $1^{\circ}$. No debería ser necesario ni la opinión médica/psicológica ni el diagnóstico de disforia de género; $2^{\circ}$. No debería ser requerida la intervención médicoquirúrgica (McKenzie et als., 2012: 153).

Las experiencias transgeneristas han llegado para plantear una encrucijada. En una época donde la explicación y terapéutica de cualquier fenómeno socialmente molesto ha sido fagocitado por esa medicina anclada en el determinismo biológico, la identidad construida sobre la premisa de una enfermedad parece contener mayores cotas de comprensión social y, además, sustenta más fácilmente la reivindicación de que los tratamiento hormono-quirúrgicos, necesarios para una parte de la población trans, queden incluidos en la cartera de servicios de los servicios nacionales de salud. Por el contrario, el estigma de la enfermedad viene a sumarse a otros a los que ha de hacer frente la población trans. No parece servir de mucho para disminuir el estigma afirmar que la psiquiatría no habla de la transexualidad como una enfermedad sino como un trastorno para ubicarla en un lugar no muy bien definido "entre la normalidad y la patología" (Gómez Gil et als, 2006: 11). Y no lo es, porque enfermedad es a enferma lo que trastorno a trastornada; y porque a estas alturas del malabarismo verbal "conviene recordar que trastornado en lenguaje coloquial, es un loco" (Nieto, 2008: 285). Y oído así, trastornado, se me antoja una palabra que no impide, sino que oculta, la acción de arrojar cualquier tipo de disidencia al cajón pestilente de lo, cuanto menos, no sano. Por último, el modelo clínico dispone que sean médicos y psicólogos quienes ostenten el poder para decidir sobre la verdadera identidad de una persona, el acceso a los tratamientos y la tutela de sus decisiones.

Cuando hablamos de despatologización de la transexualidad ni siquiera estamos planteando que no exista un sustrato biológico. Pero entre condición biológica y condición enferma se observa un salto cualitativo que ha sido gestionado por la disciplina médica en nuestro mundo social en tanto en cuanto la medicina dota de significado al dato biológico. Expresado en otros términos, el dato no es nada sin la manipulación mediada por la medicina. Sea contemplado el fenómeno de la transidentidad de una u otra manera -como condición biológica o como construcción cultural que remite al término síndrome de filiación cultural (Comelles y Martínez, 1993:87)-, el movimiento por la despatologización -y también el autor de este artículo- defiende que el derecho a la CRS es un derecho legítimo, que los servicios sanitarios públicos deben asumir los costes de estos tratamientos transexualizadores, que los profesionales sanitarios hacen lo 
que saben para aliviar el sufrimiento y que, por último, la CRS es la única salida posible para muchas personas en nuestro mundo social. Así, es necesario que los tratamientos médicos y psicológicos estén cubiertos por los sistemas de salud. De otra manera dejaría el proceso transexualizador, indispensable aún para muchas personas, en manos de una industria médico-quirúrgica que ha encontrado un importante nicho de ingresos en la construcción de cuerpos perfectamente sexuados. Y no son pocas las personas que no podrían hacer frente a los gastos derivados del proceso transexualizador exclusivamente con sus recursos económicos. Así, el movimiento STP 2012, "para facilitar la cobertura pública de la atención sanitaria trans-específica, [...] propone la inclusión de una mención no patologizante en la CIE-11", lo que se constituye como salida para posibilitar cualquier tipo de experiencia, sea o no médico-dependiente. Desde esta lógica, si es nuestro orden sociosexual el responsable del malestar y el sufrimiento de la población que no se reconoce en una identidad de género impuesta al nacimiento, es justo pedir que los tratamientos corran a cargo de los sistemas nacionales de salud.

Más allá de la importancia de saber el resultado de la reivindicación planteada en la Campaña STP 2012 -y no minusvaloro su logro-,el movimiento por la despatologización de las transidentidades visibiliza las limitaciones que impone nuestro mundo social para que consigamos tomar las riendas de nuestras vidas; nos recuerda que seguimos luchando por decidir sobre nuestros cuerpos recogiendo un histórico objetivo del movimiento feminista; nos permite contemplar la estructura y dinámicas sociales como generadoras de sufrimiento, un proceso de construcción cultural de la enfermedad oculto bajo la perversa explicación biologicista del "trastorno identitario" y del logro terapéutico basado en la acomodación del sujeto "enfermo" a la norma social "sana." En este sentido, expresado en términos foucaltianos (1977: 5), entendemos que la CRS -y la hormonación y la policirugía que acompaña a muchas experiencias trans- es una técnica que revela el carácter biopolítico de la medicina.

El movimiento STP 2012 nos enseña que, con la premisa siempre presente de no hacer daño, alcanzamos mayores cotas de libertad cuando es posible transgredir, sin obtener la respuesta social del castigo, esas nociones entendidas "de sentido común" (Bourdieu, 1995: 177); tan peligrosamente de sentido común que nos detenemos a reflexionar sobre ellas en muy raras ocasiones. Y es así que, una vez instalada la crítica trans tanto al uso de los test de género - de masculinidad y de feminidad para detectar, respectivamente, a los hombres y las mujeres de verdad-como a la imposición de las cirugías transgenitales, la reflexión sobre las nociones de sentido común puede avanzar hacia la obligatoriedad de la hormonación y del test de vida real como condiciones necesarias -y dependientes de los expertos sanitarios- para que la persona alcance el reconocimiento legal de su identidad de género. Ojalá este artículo sirva como una oportunidad para esa reflexión. 


\section{AGRADECIMIENTOS}

Deseo expresar mi gratitud a todas las personas que participaron como informantes para la elaboración de este texto. Y también deseo expresarlo a todas las personas que, de una u otra manera, con unas u otras estrategias, han dedicado parte de su tiempo, su entusiasmo y su talento a la defensa de los derechos civiles de las llamadas minorías sexuales. Especialmente a Olivier Châble en Francia y Norberto Gómez del Valle en Andalucía.

\section{REFERENCIAS BIBLIOGRÁFICAS}

ATE-Transexualia (2003) "Postura contraria de Transexualia a Campaña de Transexualidad Clínica".http://www.transexualia.org [Consultado el 29 de septiembre de 2003].

Asociación Americana de Psiquiatría (1983 [1980]) Manual Diagnóstico y Estadístico de los Trastornos Mentales (DSM-III). Barcelona: Masson.

Asociación Americana de Psiquiatría (1995 [1994]) Manual Diagnóstico y Estadístico de los Trastornos Mentales (DSM-IV). Barcelona: Masson.

Billings, Dwight; Urban, Thomas (1998 [1982]) "La construcción socio-médica de la transexualidad: interpretación y crítica". En José Antonio Nieto (Comp.) Transexualidad, transgenerismo y cultura. Antropología, identidad y género. Madrid: Talasa, pp. 91-122. Ley 3/2007, de 15 de marzo, reguladora de la rectificación registral de la mención relativa al sexo de las personas. En Yolanda Bustos (2008) La transexualidad (De acuerdo a la Ley 3/2007, de 15 de marzo). Madrid: Dykinson, pp. 333-338.

Bolin, Anne (1994) "Transcending and Transgendering: Male-to-Females Transsexuals, Dichotomy and Diversity", en Gilbert Herdt (Ed.) Third Sex. Third Gender. New York: Zone Books, pp. 447-486.

Bolin, Anne (2003 [1996]) "La transversalidad del género. Contexto cultural y prácticas de género", en José Antonio Nieto (Comp.) Antropología de la sexualidad y diversidad cultural. Madrid: Talasa, pp. 231-259.

Bourdieu, Pierre (1995) "Una duda radical". En Bourdieu, Pierre y Wacquant, Loic. Respuestas. Por una antropología reflexiva. México D.F.: Grijalbo, pp. 177-184.

Bullough, Vern (1974) "Transvestites in the Middle Ages: A sociological analysis". American Journal of Sociology, 79, pp. 1381-1394.

Bustos, Yolanda (2008) La transexualidad (De acuerdo a la Ley 3/2007, de 15 de marzo). Madrid: Dykinson.

Cabral, Mauro (2012) “Despatologizar la intersexualidad: una cuestión de derechos humanos". http://www.mulabi.org/. [Consultado el 20 de enero de 2013]

Cambasani, Olga (2003) “Test de la vida real: ¿una mujer más?”. En Antonio BecerraFernández(Dir.) Transexualidad: la búsqueda de una identidad. Madrid: Díaz de Santos, pp. 85-95. 
Cardín, Alberto (1989 [1984]) Guerreros, chamanes y travestis. Indicios de homosexualidad entre los exóticos. Barcelona: Tusquets Editores.

Chiland, Colette (1999 [1997]) Cambiar de sexo. Madrid: Ed. Biblioteca Nueva y Asociación Psicoanalítica de Madrid.

Colectiu de Transexuals de Catalunya (2003) "No a la huelga de hambre y no a la ablacionista ley de derecho a la identidad sexual". http://www.transsexualitat.org. [Consultado el 25 de mayo de 2004]

Comelles, Josep María y Martínez, Ángel (1993) Enfermedad, cultura y sociedad. Barcelona: Eudema.

Dekker, Rudolf y Van de Pol, Lotte (2006) La doncella quiso ser marinero. Travestismo femenino en Europa (siglos XVII-XVIII). Madrid: Siglo XXI.

Dreger, Alice (2001) Hermaphrodites and the Medical Invention of Sex. London: Harvard University Press.

Ehrenreich, Barbara y English, Deirdre (1984 [1973]) Brujas, comadronas y enfermeras. Dolencias y trastornos. Barcelona: La Sal.

Fausto-Sterling, Anne (2006 [2000]) Cuerpos sexuados. Barcelona: Melusina.

Fausto-Sterling, Anne (1998 [1993]) “Los cinco sexos". En José Antonio Nieto (Comp.)

Transexualidad, Transgenerismo y cultura. Antropología, identidad y género. Madrid: Talasa, pp. 79-89.

Foucault, Michel (1998a [1976a]) Historia de la sexualidad. Vol I: La voluntad de saber. Madrid: Siglo XXI.

Foucault, Michel (1990 [1977]) La vida de los Hombres Infames. Ensayos sobre desviación y dominación. Madrid: Las Ediciones de La Piqueta.

Foucault, Michel (1977) “Historia de la medicalización”, Educación médica y salud, 11 (1): pp. 1-25.

Garaizábal, Cristina (1998) "La transgresión del género. Transexualidades, un reto apasionante". En José Antonio Nieto (Comp.) Transexualidad, transgenerismo y cultura. Antropología, identidad y género. Madrid: Talasa, pp. 39-62.

Garfinkel, Harold (2006 [1967)) Estudios en Etnometodología. Barcelona: Anthropos.

Gómez Gil, E.; Esteva de Antonio, I. y Bergero, T. (2006) "La transexualidad, transexualismo o trastorno delaidentidad de género en el adulto: Concepto y características básicas". C. Med. Psicosom, 78, pp. 7-12.

Guasch, Óscar (2000) La crisis de la heterosexualidad. Barcelona: Laertes.

Guillaumin, Colette (1992) Sexe, race et practique de pouvoir. París: Coté-Femmes.

Hamburger, C.; Sturup, G.K. y Dahl-Iversen, E. (1953) "Trans-vestism: Hormonal, Psychiatric and Surgical Treatment". Journal of the American Medical Association, 152, pp. 391-396.

Hamburger, Christian (1953) "Desire for change of sex as shown by personal letters from 465 men and women”. Acta Endocrinologica, 14, pp. 361-375. 
Hausman, Bernice (1998 [1992]) "En busca de la subjetividad: transexualidad, medicina y tecnologías de género". En José Antonio Nieto (Comp.) Transexualidad, transgenerismo y cultura. Antropología, identidad y género. Madrid: Talasa, pp. 193-232.

Jorgensen, Christine (1967) Christine Jorgensen: A personal Autobiography. New York: Bantam Books.

Kessler, Suzanne (1990) "The medical construction of gender: case management of intersexed infants". Journal of Women in Culture and Society, 16 (1), pp. 3-26.

Kleinman, Arthur (1980) Patients and Healers in the Context of Culture. An exploration of the Borderland between Anthropology, Medicine and Psychiatry. Berkeley (California): University of California Press.

Ley 26743 (2012) (Ley de identidad de género en Argentina). http://www 1.hcdn.gov.ar/ dependencias/dsecretaria/Leyes/26743.pdf [Consultado el 12 de enero de 2013]

Mackenzie, Gordene (1994) Transgender Nation. Bowling Green (Ohio): Bowling Green State University Popular Press.

Mackenzie, C.; Paradis, E.; Agius, S.; Lavrikovs, J. (Ed.) (2012) Annual Review of the Human Rights Situation of Lesbian, Gay, Bisexual, Trans and Intersex People in Europa. 2011. Bruselas: ILGA-EUROPA. http://www.liga-europe.org. [Consultado el 20 de enero de 2013]

Martin, M. Kay y Voorhies, Barbara (1978 [1975]) La mujer: Un enfoque antropológico. Barcelona: Anagrama.

Mathieu, Nicole Claude (1991 [1989]) "Identité sexuelle/sexuée/de sexe?". En L'anatomie politique. Categorizations et ideologies du sexe. París: Côte-femmes editions, pp. 227-266.

Martínez, Moisés (2002) "El concepto de uno mismo como transexual gay y el mundo homosexual. El armario y la falocracia". I Encuentros Estatales Mixtos de Transexuales, Valencia [comunicación personal].

Mejía, Norma (2005) Transgenerismos. Una experiencia transexual desde la perspectiva antropológica. Barcelona: Bellaterra.

Missé, Miquel y Solá, Miriam (2009) "La lucha trans por la despatologización. Una lucha transfeminista". Jornadas Feministas Estatales, Granada, 2009. http://www.feministas. org/ [Consultado el 20 de enero de 2013].

Missé, Miquel y Coll-Planas, Gerard (Eds) (2010) El género desordenado: críticas en torno a la patologización de la transexualidad. Barcelona: Egales.

Nanda, Serena (2000) Genderdiversity. Crosscultural Variations. Illinois (USA): Waveland Press.

Nieto, José Antonio (2008) Transexualidad, intersexualidad y dualidad de género. Barcelona: Bellaterra.

Nieto, José Antonio (1998) (Comp.) Transexualidad, transgenerismo y cultura. Antropología, identidad y género. Madrid: Talasa. 

las Enfermedades (CIE-10). Madrid: Meditor.

Pierrot (Antoni Gracia José) (2006) (2006b) “Murieron con las plumas puestas". Revista Zero, 91, pp. 95.

Ramet, Sabrina (1996) (Ed.) Gender Reversals and Gender Cultures. Anthropological and Historical Perspectives. London: Routledge.

Ramos, Juana (2009) "En busca de la esencia perdida: las identidades desde una perspectiva trans". Jornadas Feministas Estatales, Granada, 2009. http://feministas.org [Consultado el 20 de enero de 2013].

Ramos, Juana (2004) "Una visión feminista de la transexualidad". En Mayte Ayllón (Comp.) Transexualidad, transgeneridad y feminismo. Madrid: Genera-TransexualiaCOGAM, Mujeres y Teología de Madrid, pp. 81-90.

Ramos, Juana (2003) "Las asociaciones de transexuales en España". En Antonio Becerra-Fernández (Dir.) Transexualidad: la búsqueda de una identidad. Madrid: Díaz de Santos, pp. 125-142.

Raymond, Janice (1980 [1979]) The Trassexual Empire. London: The Women`s Press Limited.

Stone, Sandy (1991) "The "empire" strikes back: A post-transsexual manifesto". En Kristina Straub y Julia Epstein (Eds.) Body guards: The cultural politics of gender ambiguity. New York: Routledge, pp. 121-142.

STP, Campaña Internacional Stop Trans Pathologization. http://www.stp2012.es [Consultado el 20 de abril de 20113].

Szasz, Thomas (1994 [1961] El mito de la enfermedad mental. Buenos Aires: Amorrortu Tena, Fernando (2010) Género, salud y orden social. El caso del modelo clínico de transexualidad en Andalucía. Sevilla: Centro de Estudios Andaluces, Consejería de Presidencia.

Vázquez García, Francisco (1999) "Los límites del discurso “progresista”. El Viejo Topo, 135, pp. 35-39.

Warren, Barbara (1998 [1993) “Transexualidad, identidad y adquisición de poder. Visión desde la primera línea". En José Antonio Nieto (Comp.) Transexualidad, transgenerismo y cultura. Antropología, identidad y género. Madrid: Talasa, pp. 337-350.

Wekks, Jeffrey (1993) El malestar de la sexualidad. Significados, mitos y sexualidades modernas. Madrid: Talasa.

Wittig, Monique (2006[1992]) El pensamiento heterosexual y otros ensayos. Madrid/ Barcelona: Egales.

Whittle, Stephen (2000) The Transgender Debate. The Crisis Surrounding Gender Identities. Reading: South Street Pres.

Zhou, J.N.; Hofman, M.A.; Gooren L.J.G.; Swaab, D.F. (1995) “A sex difference in the human brain and its relation to transsexuality". Nature, 378, pp. 68-70. 